\title{
Thermal Stability and Degradation of Chitosan Modified by Cinnamic Acid
}

\author{
Mostafa Amin Diab ${ }^{1}$, Adel Zaki El-Sonbati ${ }^{1}$, Mohamed Mohamed Al-Halawany ${ }^{2}$, \\ Dina Mohamed Diaa Bader ${ }^{1}$ \\ ${ }^{1}$ Chemistry Department, Faculty of Science, Mansoura University, Damietta, Egypt \\ ${ }^{2}$ Engineering Mathematics and Physics Department, Faculty of Engineering, Mansoura University, Mansoura, Egypt \\ Email: m.adiab@yahoo.com
}

Received December 28, 2011; revised January 27, 2012; accepted February 5, 2012

\begin{abstract}
The reaction of chitosan with cinnamic acid gave the corresponding N-cinnamoyl chitosan (NCC) polymer. The chemical structure of the modified polymer was characterized by IR, ${ }^{1} \mathrm{H}-\mathrm{NMR}$ and elemental analysis. Thermogravimetric analysis reveals that the thermal stability of chitosan polymer is greater than NCC polymer. The activation energies of thermal degradation of chitosan and NCC polymers were determined using Arrhenius relationship. Thermal degradation of NCC polymer was studied and the products of degradation were identified by GC-MS technique. It seems that the mechanism of degradation of NCC polymer is characterized by elimination of low-molecular weight radicals. Combination of these radicals and random scission mechanism along the backbone chain are the main source of the degradation products.
\end{abstract}

Keywords: N-Cinnamoyl Chitosan Preparation; Thermal Stability and Degradation; Mechanism of Degradation

\section{Introduction}

Chitosan is a kind of fine biomaterial obtained by deacetylation of naturally occurring polymer chitin. It consists of $\beta$-(1,4)-2-amino-2-deoxy-D-glucopyranose units (GKN) and a small amount of 2-acetamido-2-deoxy-D-glucopyranose or N-acetyl-D-glucosamine (GKNAc) residues. Furthermore, chitosan is also a non-toxic, biodegradable, and biocompatible polymer, which is reported to exhibit a great variety of useful biological properties. However, its biological activity appears only in acidic medium because of its poor solubility in neutral and basic $\mathrm{pH}$. To increase water solubility, the chemical modifications of chitosan have been applied [1]. The free amino groups of chitosan enable a veriety of chemical modifications and substitution process like carboxyalkylation, acylation, sulfation, cyanoethylation, nitration, phosphorylation, enzymatic substitution, metal chelation, Schiff's base, etc [25]. Furthermore, various properties of the modified chitosan have been used in many applications such as absorption enhancement in caco-2-merbane model [6], gene [7], drug or protein delivery [8,9], waste-water treatment [10], food industry [11], gel implants [12], scaffolding material [13] and in medicine as wound dressing and drug delivery $[14,15]$. It has been reported that chitosan is more stable than chitin to depolymerization due to stabilizing effect of the free amino group [16]. In spit to that, it was found that chitosan at high temperature in air un- dergo degradation [17]. Thermal analysis with derivatograph showed that this polymer can not withstand temperature higher that $200^{\circ} \mathrm{C}-220^{\circ} \mathrm{C}$. Diab et al. [18, 19] was reported the reaction of chitosan with benzophenone and acetophenone. The thermal stability and degradation behaviours of these modified has been reported polymers. In this paper, N-cinnamoyl chitosan (NCC) polymer was synthesized via a Schiff reaction of chitosan with cinnamic acid. The formed modified polymer was characterized by elemental analysis $(\mathrm{C}, \mathrm{H}, \mathrm{N})$, IR spectroscopy and thermal gravimetric analysis. Thermal degradation of NCC polymer was studied and the products of degradation were identified by GC-MS technique. Mechanism of degradation is suggested.

\section{Experimental}

\subsection{Materials}

Chitosan (Aldrich Chemical Co., Inc.) was used without further purification. Its degree of deacetylation (DDA) was determined to be $94 \%$ by ${ }^{1} \mathrm{H}-\mathrm{NMR}$ spectroscopic method [20,21]. The molecular weight distribution and subsequent characteristics were obtained in an AVS-350 viscometer coupled to an automatic dilution device Scholl Gerate ViscoDoser AVS 20. The molecular weight of the chitosan was estimated based on the parameters described by Mark-Houwink equation [22]: 


$$
[\eta]=\mathrm{K}_{\mathrm{m}} \mathrm{M}^{\mathrm{a}}
$$

where $\mathrm{K}_{\mathrm{m}}=0.076$ and $\mathrm{a}=0.76$. The average viscometric molecular weight $\mathrm{M}_{\mathrm{v}}=69000$ was estimated from the intrinsic viscosity determined in a $0.3 \mathrm{~mol} \cdot \mathrm{L}^{-1}$ acetic acid and $0.2 \mathrm{~mol} \cdot \mathrm{L}^{-1}$ sodium acetate buffer solution at $25 \pm$ $0.01^{\circ} \mathrm{C}$ as the mean of five replicates.

Cinnamic acid (BDH Chemical Ltd.) was purified by standard procedure.

All other chemicals and solvents were purified by standard procedure.

\subsection{Preparation of the Polymer}

An equimolar ratio of chitosan and cinnamic acid was fused for $30 \mathrm{~min}$, then $50 \mathrm{ml}$ of glacial acetic acid was added to the reaction mixture and refluxed for $2 \mathrm{~h}$. The excess acetic acid was removed by distillation. The reaction mixture was cooled to room temperature and washed with diethyl ether and methanol to remove the unreacted cinnamic acid. The formed solid polymer was filtered and dried in an oven at $40^{\circ} \mathrm{C}$ for several days.

\subsection{Analytical Techniques}

\subsubsection{Infrared Spectroscopy (IR)}

Spectra of the polymer samples in the form of $\mathrm{KBr}$ discs were recorded on Pye Unicam SP 2000 spectrometer.

\subsubsection{Nuclear Magnetic Resonance Spectroscopy ( ${ }^{1} \mathrm{H}$ NMR)}

The ${ }^{1} \mathrm{H}$ NMR spectrum of chitosan was measured on a Varian EM $39090 \mathrm{MHz}$ spectrometer with integration and $10 \mathrm{mg}$ sample. The polymer was dissolved in $\mathrm{D}_{2} \mathrm{O} /$ $\mathrm{CF}_{3} \mathrm{COOD}$. The integral obtained was used for the determination of DDA.

\subsubsection{Microanalysis}

Elemental analysis of the modified polymer was performed by Microanalytical Unit at Cairo University.

\subsubsection{Thermal Gravimetric Analysis (TG)}

TG measurements were made with a Mettler TG 3000 apparatus. Finely powdered ( $\sim 10 \mathrm{mg})$ samples were heated at $10 \% \mathrm{~min}$ in a dynamic nitrogen atmosphere (30 $\mathrm{ml} / \mathrm{min}$ ); the sample holder was boot-shaped, $10 \mathrm{~mm} \times 5$ $\mathrm{mm} \times 2.5 \mathrm{~mm}$ deep and the temperature measuring thermocouple was placed $1 \mathrm{~mm}$ from the sample holder.

TG was also used for the determination of rates of degradation of the polymer in the initial stages of decomposition. The activation energies were calculated by application of the Arrhenius equation.

\subsubsection{Thermal Degradation of the Polymer}

Samples of $\sim 50 \mathrm{mg}$ were heated under vacuum from ambient temperature to $500^{\circ} \mathrm{C}$. The volatile degradation products were collected for qualitative analysis by GC-MS technique. A Saturn GC 3400 with a fused quartz capillary column of $30 \mathrm{~m} \times 0.25 \mathrm{~mm}$ coated with methyl silicon, using flame ionization analyzer was used for identification of the condensable degradation products. The carrier gas was nitrogen at a flow rate $20 \mathrm{ml} / \mathrm{min}$ and the programmed heating rate of $10^{\circ} / \mathrm{min}$ from $40^{\circ} \mathrm{C}$ to $200^{\circ} \mathrm{C}$. The GC is interfaced with a Varian mass spectrometer equipped with the standard electron impact or chemical ionization (CI) source and a DS 55 data system scanned from $\mathrm{m} / \mathrm{e} 200$ to 20 at a scan rate of $10 \mathrm{~s} /$ decade. Perfluorokerosene (PFK) was used for computer calibration; the ion source was maintained at $200^{\circ} \mathrm{C}$. Accurate mass measurements in CI mass spectra were performed at 10000 resolving power using PFK as internal reference and by computer interpolation data system.

\section{Results and Discussion}

\subsection{Characterization of N-(Cinnamoyl) (NCC) Chitosan Polymer}

The IR spectrum of chitosan shows a broad band at 3423 $\mathrm{cm}^{-1}$ due to $\mathrm{OH}$ and $\mathrm{NH}_{2}$ groups. The bands at 1655 and $1321 \mathrm{~cm}^{-1}$ due to the amino group. There are bands at 1458, 1423, 1379 and $1078 \mathrm{~cm}^{-1}$ due to O-C-O group. These bands are in good agreement with the IR spectrum of chitosan reported by Muzzorella et al. [23] and Brugnerotto et al. [14]. Microanalysis of $\mathrm{C}_{6} \mathrm{H}_{11} \mathrm{O}_{4} \mathrm{~N}$ (Calcd. C, 44.7; H, 6.8; N, 8.7\%. Found C, 44.62; H, 6.94; N, $8.67 \%)$.

The reaction of chitosan with cinnamic acid give the corresponding N-cinnamoyl chitosan (NCC) polymer.
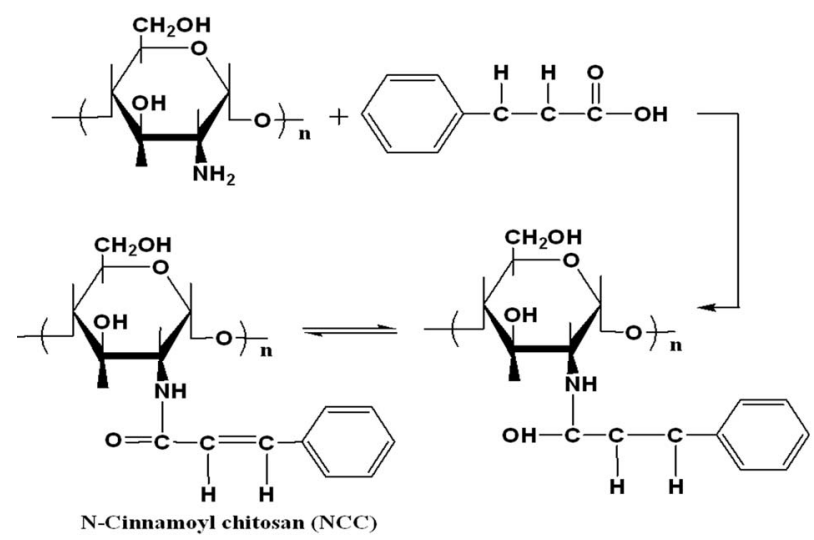

The IR spectrum of NCC polymer shows the presence of amidic carbonyl group at $\sim 1700 \mathrm{~cm}^{-1}$ indicating the involvement of cinnamic acid in the modification of chitosan. The absorption at $711 \mathrm{~cm}^{-1}$ are due to the $\mathrm{C}=\mathrm{C}$ stretching in the aromatic ring. Microanalysis of NCC polymer $\mathrm{C}_{15} \mathrm{H}_{17} \mathrm{O}_{4} \mathrm{~N}$ (Calcd. C, 65.4; H, 6.2; N, 5.1\%. 
Found $\mathrm{C}, 64.81 ; \mathrm{H}, 6.35 ; \mathrm{N}, 4.81 \%$ ). The elemental analysis results of chitosan and NCC polymers are quiet different from those expected for a $100 \%$ degree of substitution $(\sim 90 \%)$, suggesting that the substitution is not complete. However the presence of cinnamic acid in chitosan modification caused an increase in the carbon and hydrogen content in the resulting material compared with the starting chitosan. A decrease in nitrogen/carbon ratio suggests that the substitution occurred.

\subsection{Thermal Methods of Analysis}

\subsubsection{Thermogravimetry (TG)}

TG curve of chitosan is shown in Figure 1. There are two degradation stages in chitosan polymer. In the first stage, weight loss starts at $\sim 220^{\circ} \mathrm{C}$ and continues to $\sim 320^{\circ} \mathrm{C}$ with $\sim 50 \%$ weight loss. The maximum rate of weight loss, shown by derivative equipment associated with TG apparatus, occurs at $\sim 295^{\circ} \mathrm{C}$. The second stage reaches a maximum at $\sim 470^{\circ} \mathrm{C}$ with a weight loss percentage of $\sim 40 \%$.

There are two degradation stages in NCC polymer as shown in Figure 2. The first stage starts at $\sim 145^{\circ} \mathrm{C}$ with a weight loss percentage of $\sim 50 \%$. The maximum rate of weight loss at $\sim 360^{\circ} \mathrm{C}$ with a weight loss percentage of $\sim 44 \%$. TG curves of NCC and chitosan polymers reveal that chitosan is more thermally stable than NCC polymer.

The effective activation energies of the thermal degradation of chitosan and NCC polymers were determined from the temperature dependence of the chain repture rate. The rate constant of the thermal degradation plotted according to the Arrhenius relationship (Figure 3). The activation energies of the chitosan and NCC polymers

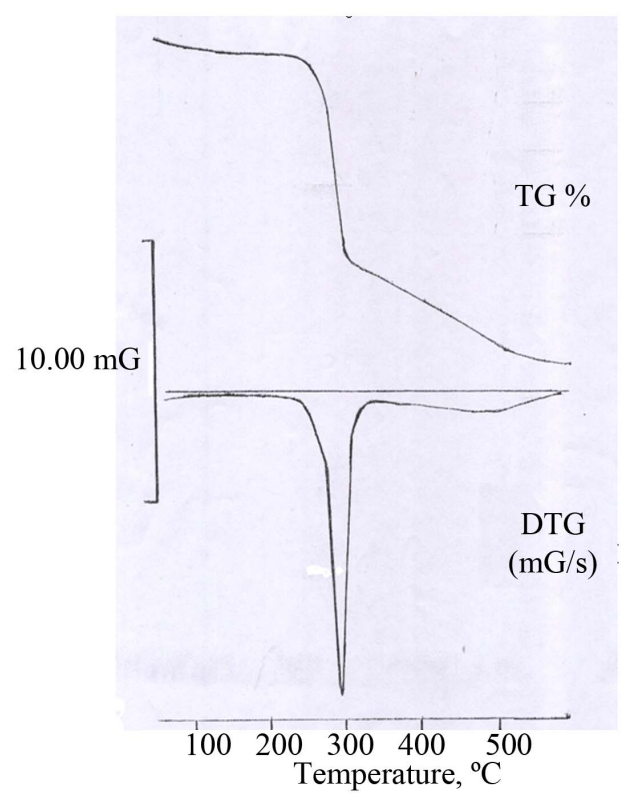

Figure 1. TG curve of chitosan.

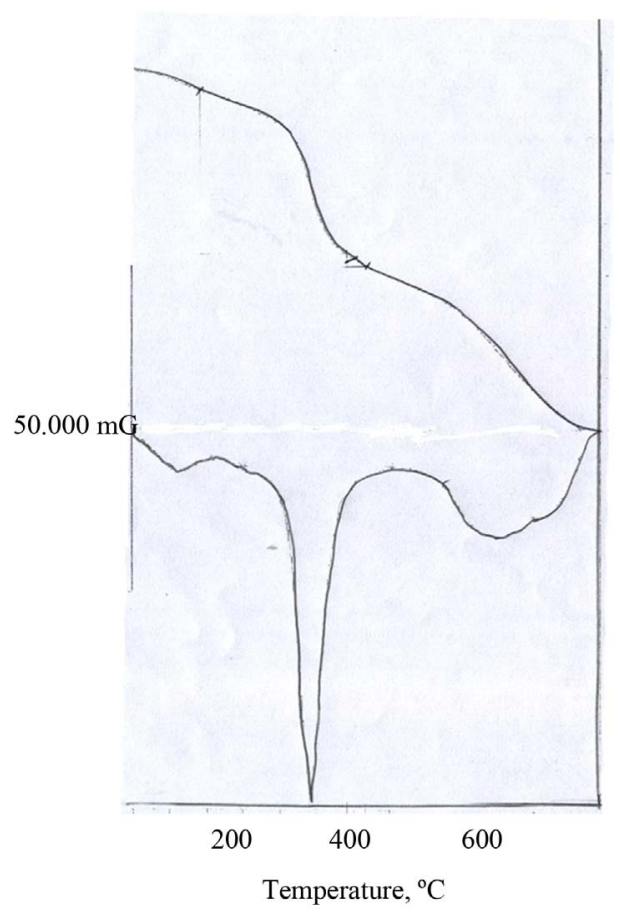

Figure 2. TG curve of NCC polymer.

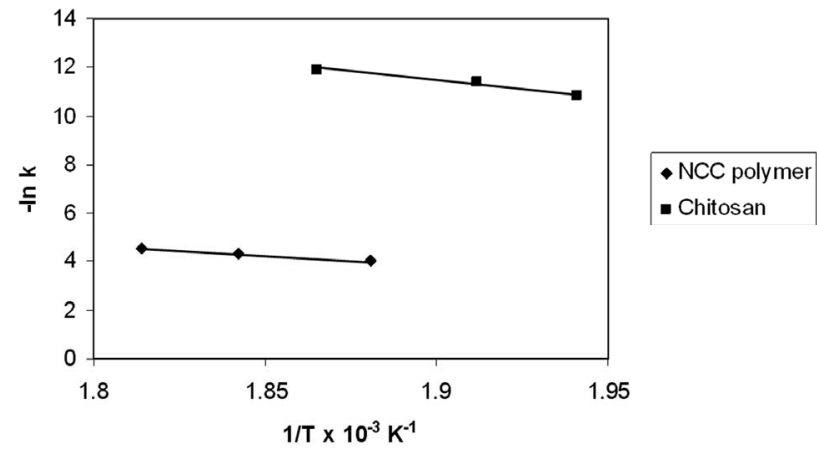

Figure 3. Arrhinus plots of the rate constants of degradation of chitosan and NCC.

were found to be 52.2 and $32.7 \mathrm{KJ} / \mathrm{mol}$, respectively. The smaller value of the activation energy of NCC than chitosan polymers indicates that the stabilities are in the same order of activation energies. Therefore, NCC polymer should undergo decomposition more readily than chitosan.

\subsubsection{Thermal Degradation of NCC Polymer}

The liquid fraction of the degradation of NCC polymer was injected into the GC-MS apparatus. Figures 4 (a) and (b) shows the GC trace of the liquid product of degradation of NCC polymer to $500^{\circ} \mathrm{C}$. Table 1 represents the results of degradation products which were identified by mass spectroscopy. From the degradation products it seems that the degradation of NCC polymer is characterized by the formation of low-molecular weight radicals, 


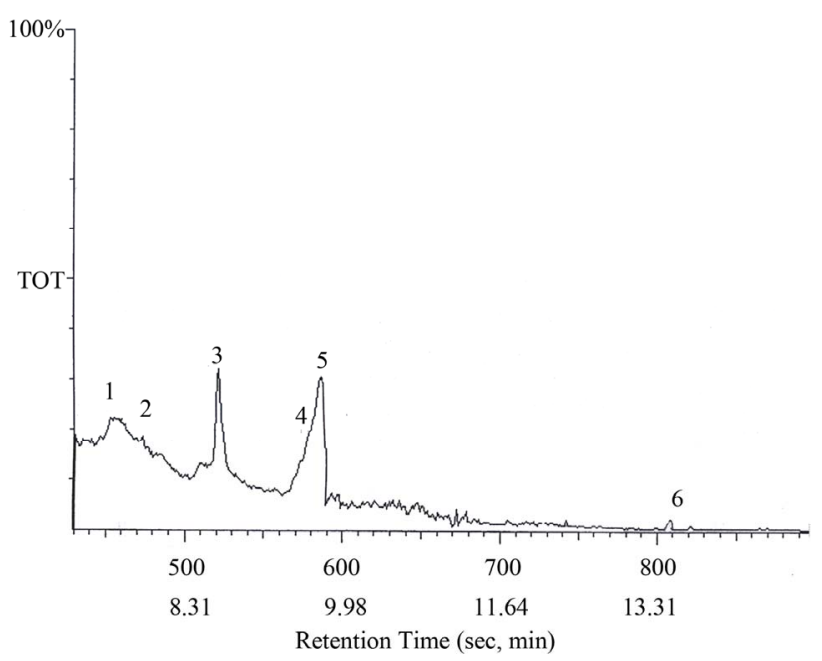

(a)

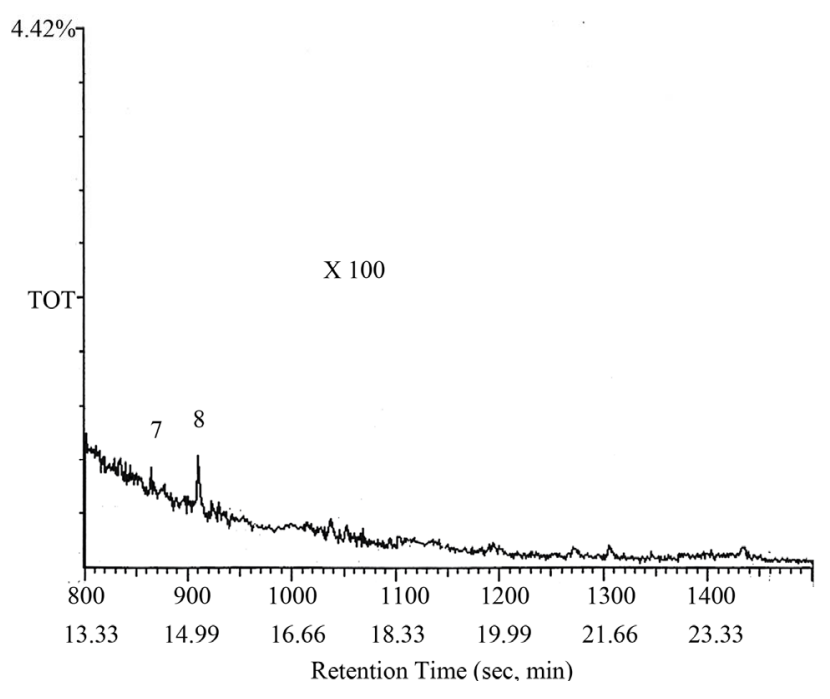

(b)

Figure 4. GC curve of the degradation products of NCC polymer.

Table 1. GC-MS of the degradation products of NCC polymer

\begin{tabular}{cccc}
\hline Peak No. & $\begin{array}{c}\text { Retention } \\
\text { Time, min. }\end{array}$ & $\begin{array}{c}\text { Major MS } \\
\text { Fragments }\end{array}$ & $\begin{array}{c}\text { Suggested Structures } \\
\text { (Most Probable) }\end{array}$ \\
\hline 1 & 7.49 & $84,61,47$ & 5-Hydroxy-1,3-Pentadiene \\
2 & 7.69 & $95,70,47$ & Cyclohex-1-en-6-ol \\
3 & 8.70 & $102,83,61,47$ & 4,5-Dihydroxypent-1-ene \\
4 & 8.95 & $106,91,71,48$ & 1-Ethylbenzene \\
5 & 9.44 & $112,63,56$ & 6-Hydroxy-2,4-hexadinol \\
6 & 13.38 & $\begin{array}{c}148,132,114, \\
6\end{array}$ & 3,5,6-Trihydroxyhexanol \\
7 & 14.33 & $\begin{array}{c}147,132,115, \\
100,75,61\end{array}$ & cinnamide \\
8 & 14.97 & $150,109,75,61$, & 3-phenylpropanoic acid \\
\hline
\end{tabular}

followed by random scission mechanism along the backbone chain.
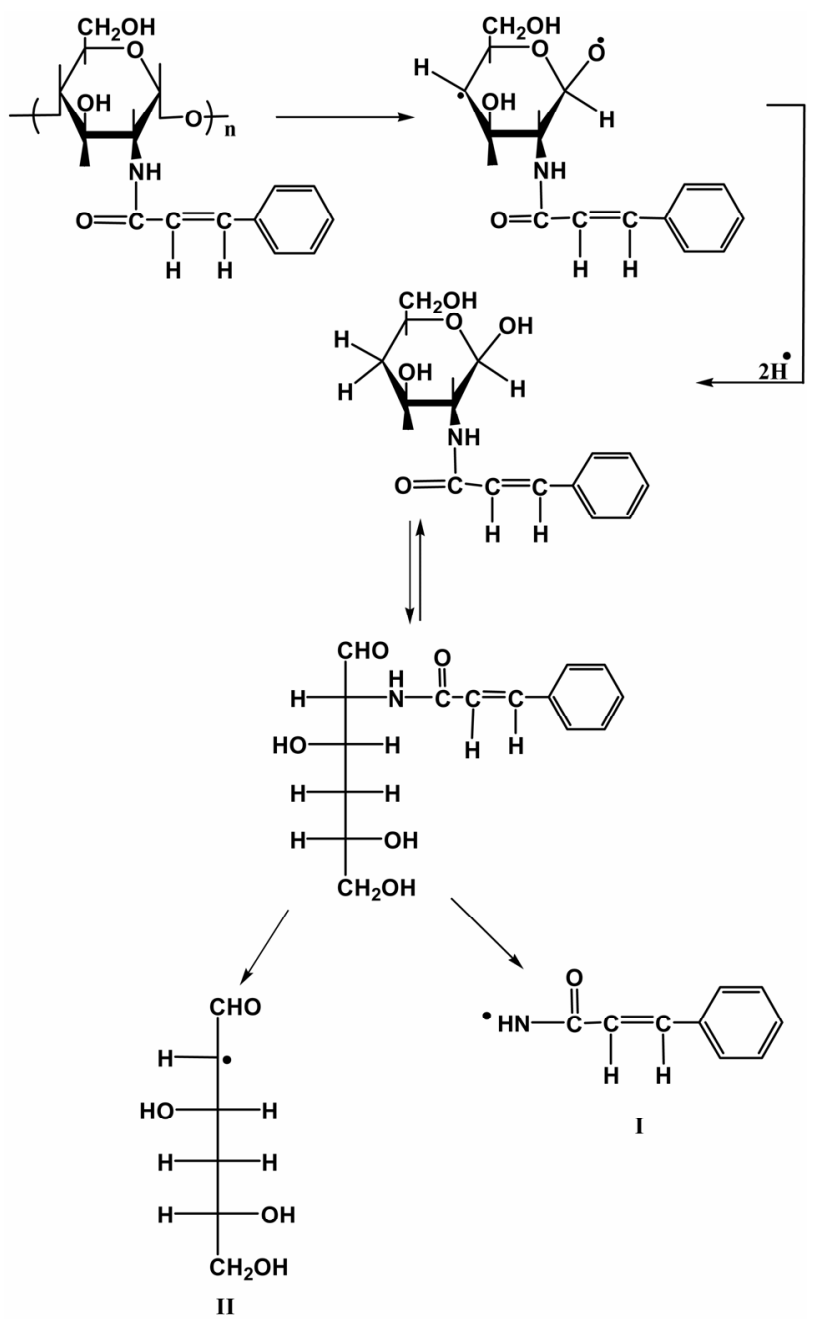

The radical I may abstract $\mathrm{H}^{*}$ to produce cinnamide (Peak 7).

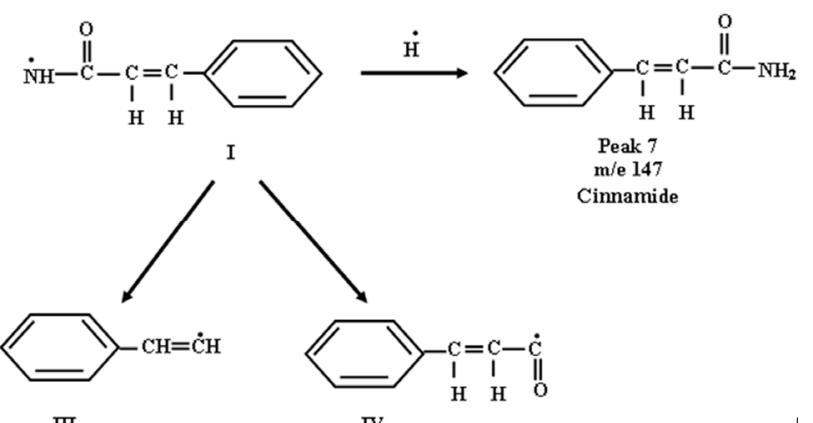

III

IV

The radical III may abstract $3 \mathrm{H}^{\prime}$ to produce 1-ethylbenzene as shown in peak 4 in Figure 4.

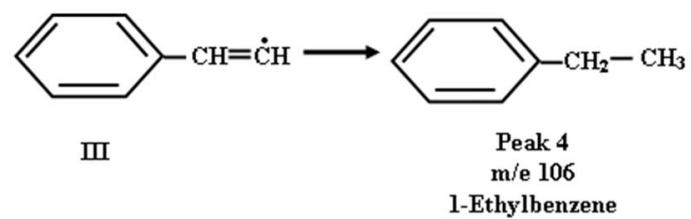


3-Phenylpropanoic acid was formed from the radical IV (Peak 8), which was confirmed by mass spectroscopy.

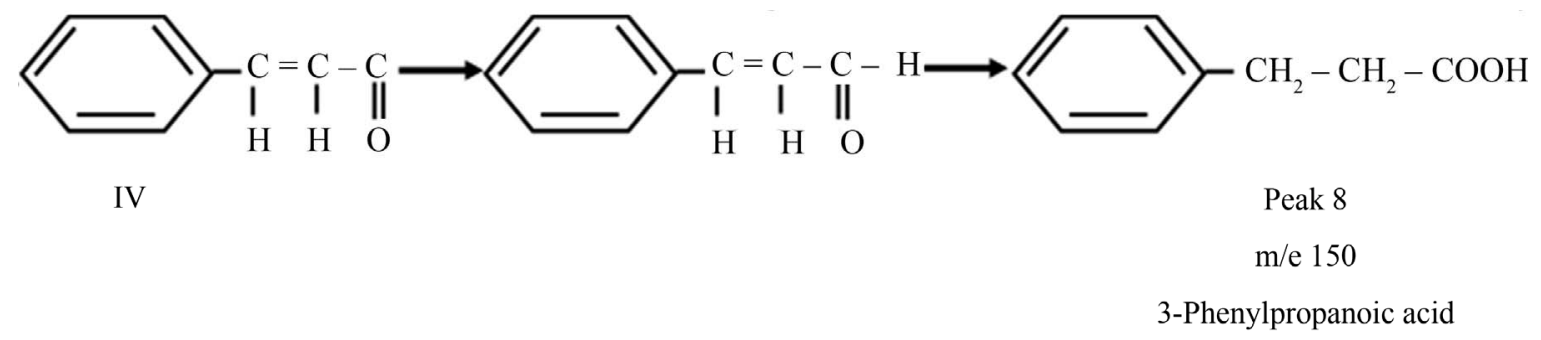

The aldehydic radical II may abstract $\mathrm{H} \cdot$ to form 3,5,6-trihydroxyhexanol (Peak 6).

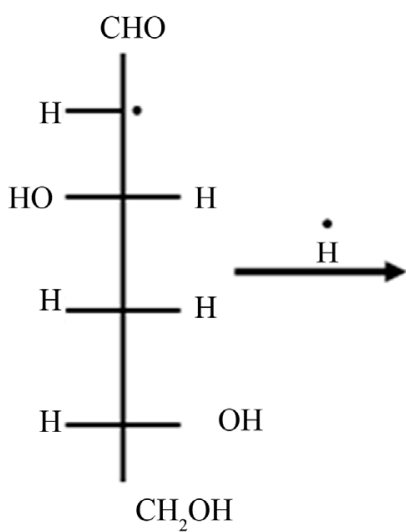

II<smiles>CC(O)CC(O)C(C)C=O</smiles>

$\mathrm{CH}_{2} \mathrm{OH}$

Peak 6

$\mathrm{m} / \mathrm{e} 148$

3,5,6-Trihy droxyhexanol

3,5,6-Ttrihydroxyherxanol may lose two molecules of water or formic acid forming 4,5-dihydroxypent-1-ene and 6-hydroxy-2,4-hexadienol (Peaks 3 and 5, respectively). 4,5-Dihydroxypent-1-ene may lose a molecule of water to form 5-hydroxy-1,3-pentadiene (Peak 1).

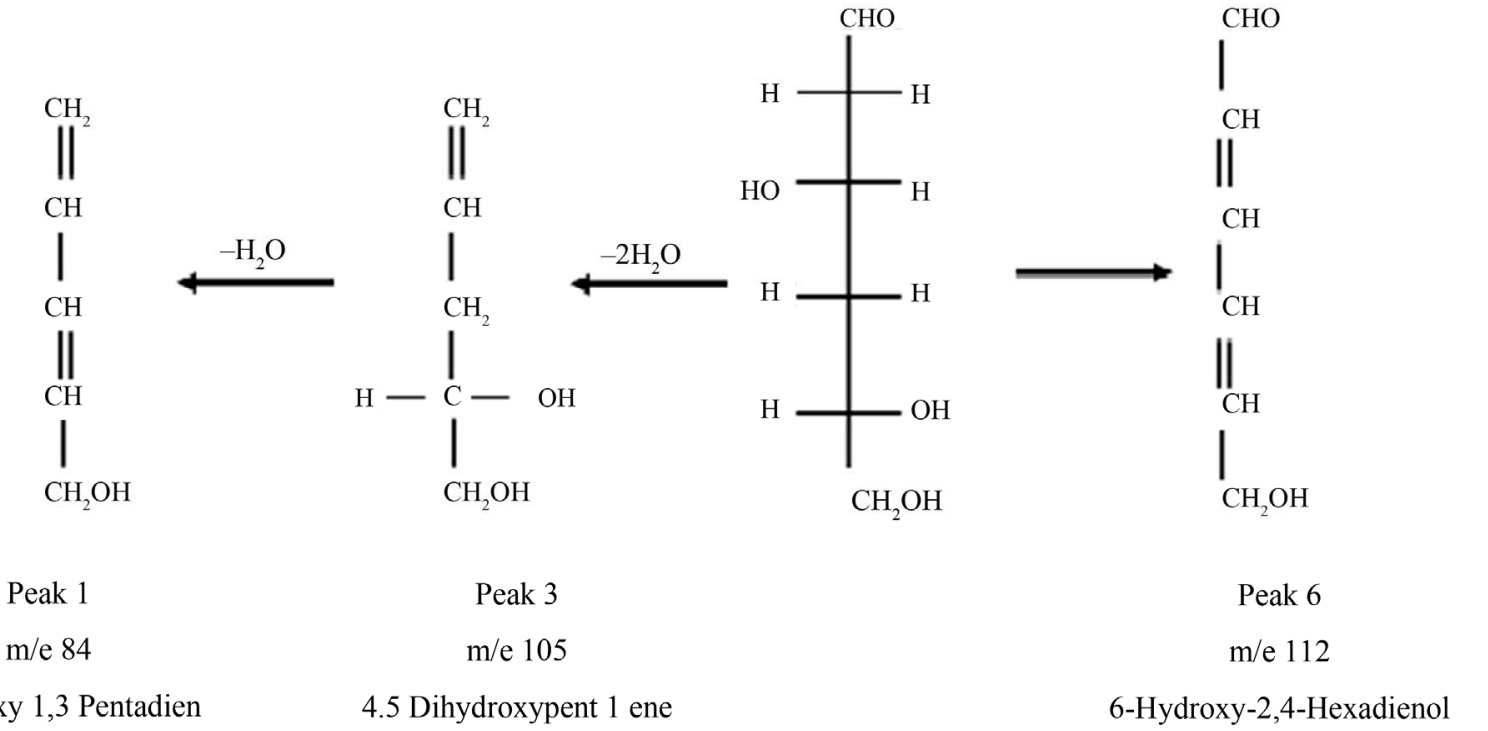

5Hydroxy 1,3 Pentadien 4.5 Dihydroxypent 1 ene 6-Hydroxy-2,4-Hexadienol

The enolic form of 3,5,6-trihydroxyhexanol may cyclized to form cyclohex-1-en-6-ol as shown in peak 2. 


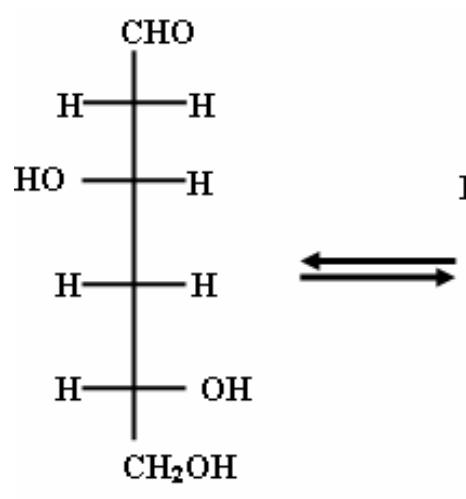

\section{Conclusion}

N-Cinnamoyl chitosan (NCC) polymer was synthesized via a Schiff reaction of chitosan with cinnamic acid. The formed modified polymer was characterized by elemental analysis $(\mathrm{C}, \mathrm{H}, \mathrm{N})$, IR spectyroscopy and the thermal stability was compared with chitosan. Thermal degradation of the NCC polymer was studied and the degradation products were identified by GC-MS technique. 5-Hydroxy-1,3-pentadiene, cyclohex-1-en-6-ol, 4,5-dihydroxypent-1-ene, 1-ethylbenzene, 6-hydroxy-2, 4-hexadinol, 3, 5,6-trihydroxyhexanol, cinnamide and 3-phenylpronoic acid were the main degradation products. Accordingly, it seems that the mechanism of degradation of NCC polymer is characterized by elimination of low-molecular weight radicals. Combination of these radicals and random scission mechanism along the backbone chain are the main source of the degradation products.

\section{REFERENCES}

[1] W. Sajomsang, P. Gonil and S. Saesoo, "Synthesis and Antibacterial Activity of Methylated $N$-(4- $N, N$-Di-methylaminocinnamyl) Chitosan Chloride," European Polymer Journal, Vol. 45, No. 8, 2009, 2319-2328. doi:10.1016/j.eurpolymj.2009.05.009

[2] V. V. Binsu, R. K. Nagarate, V. K. Shahi and P. K-Glosh, "Studies on $N$-Methylene Phosphonic Chitosan/Poly(Vinyl Alcohol) Composite Proton-Exchange Membrane," Reactive and Functional Polymers, Vol. 66, No. 12, 2006, pp. 1619-1629. doi:10.1016/j.reactfunctpolym.2006.06.003

[3] D. Britto and O. B. G. Assis, "A Novel Method for Obtaining a Quaternary Salt of Chitosan," Carbohydrate Polymers, Vol. 69, No. 2, 2006, pp. 305-310. doi:10.1016/j.carbpol.2006.10.007

[4] H. K. V. Pashanth and R. N. Tharanathan, "Chitin/Chitosan: Modifications and Their Unlimited Application Potential an Overview," Trends in Food Science Technology, Vol. 18, No. 3, 2007, pp. 117-131.

[5] F. A. A. Tirkistani, "Thermal Analysis of Some Chitosan Schiff Bases," Polymer Degradation and Stability, Vol. 60, No. 1, 1998, pp. 67-70. doi:10.1016/S0141-3910(97)00020-7
[6] M. M. Thanou, J. C. Verhoef, S. G. Romeijn, J. F. Nagelkerke, K. Merkus and H. E. Junginger, "Effects of $N$-Trimethyl Chitosan Chloride, A Novel Absorption Enhancer, on Caco-2 Intestinal Epithelia and the Ciliary Beat Frequency of Chicken Embryo Trachea," International Journal of Pharmaceutics, Vol. 185, No. 1, 1998, pp. 73-82. doi:10.1016/S0378-5173(99)00126-X

[7] T. Kean, S. Roth and M. Thanou, "Trimethylated Chitosans as Non-Viral Gene Delivery Vectors: Cytotoxicity and Transfection Efficiency," Journal of Controlled Release, Vol. 103, No. 3, 2005, pp. 643-653.

doi:10.1016/j.jconrel.2005.01.001

[8] S. Cafaggi, E. Russo, R. Stefani, R. Leadi, G. Cavigliodi and B. Paradi, "Preparation and Evaluation of Nanoparticles Made of Chitosan or $N$-Trimethyl Chitosan and a Cisplatin-Alginate Complex," Journal of Controlled Release, Vol. 121, No. 1-2, 2007, pp. 110-123. doi:10.1016/j.jconrel.2007.05.037

[9] C. Fu, Z. Zhi-Rong, Y. Fang, Q. Xuan, W. Minting and H. Yuan, "In Vitro and in Vivo Study of $N$-Timethyl Chitosan Nanoparticles for Oral Protein Delivery," International Journal of Pharmaceutics, Vol. 349, No. 1-2, 2008, pp. 226-233. doi:10.1016/j.ijpharm.2007.07.035

[10] G. Crini, "Recent Developments in Polysaccharide-Based Materials Used as Adsorbents in Wastewater Treatment," Journal of Polymer Science, Vol. 30, No. 1, 2005, pp. 38-70.

[11] E. Agullo, M. S. Rodtiquez, V. Ramos and L. Albertengo, "Present and Future Role of Chitin and Chitosan in Food," Macromolecular Bioscience, Vol. 3, No. 10, 2003, pp. 521-530. doi:10.1002/mabi.200300010

[12] A. Chenite, C. Chaput, D. Wang, C. Cambes, M. D. Buschmann, C. D. Hoemann, J. C. Leroux, B. L. Atkinson, F. Binette and A. Selmani, "Novel Injectable Neutral Solutions of Chitosan form Biodegradable Gels in Situ," Biomaterials, Vol. 21, No. 21, 2000, pp. 2155-2161. doi:10.1016/S0142-9612(00)00116-2

[13] S. H. Hsu, S. W. Whu, C. L. Tsai, Y. H. Wu, H. W. Chem and K.H. Hsieh, "Chitosan as Scaffold Materials: Effects of Molecular Weight and Degree of Deacetylation," Journal of Polymer Research, Vol. 11, No. 2, 2004, pp. 141147. doi:10.1023/B:JPOL.0000031080.70010.0b

[14] H. Sashiwa and S. I. Aiba, "Chemically Modified Chitin and Chitosan as Biomaterials," Progress in Polymer Science, Vol. 29, No. 9, 2004, pp. 887-908. 
doi:10.1016/j.progpolymsci.2004.04.001

[15] M. Huang, E. Khora and L. Y. Lim, "Uptake and Cytotoxicity of Chitosan Molecules and Nanoparticles: Effects of Molecular Weight and Degree of Deacetylation," Pharmaceutical Research, Vol. 29, No. 2, 2004, pp. 344-353. doi:10.1023/B:PHAM.0000016249.52831.a5

[16] M. Bihair-varga, C. Spulchre and E. Moczar, "Thermoanalytical Studies on Protein-Polysaccharide Complexes of Connective Tissue," Journal of Thermal Analysis and Calorimetry, Vol. 17, No. 2, 1975, pp. 675-683

[17] F. A. A. Tirkistani, "Thermal Analysis of Some Chitosan Schiff Bases," Polymer Degradation and Stability, Vol. 60, No. 1, 1988, pp. 67-70. doi:10.1016/S0141-3910(97)00020-7

[18] M. A. Diab, A. Z. El-Sonbati and D. M. D. Bader, "Thermal Stability and Degradation of Chitosan Modified by Benzophenone," Spectrochimica Acta Part A, Vol. 79, No. 5, 2011, pp. 1057-1062. doi:10.1016/j.saa.2011.04.019

[19] M. A. Diab, A. Z. El-Sonbati, D. M. D. Bader and M. Sh. Zoromba, "Thermal Stability and Degradation of Chitosan Modified by Acetophenone," Journal of Polymers and the Environment.
[20] E. Ferandez-Megia, R. Novaa-Carbollal, E. Quinoa and R. Riguera, "Optimal Routine Conditions for the Determination of the Degree of Acetylation of Chitosan by $1 \mathrm{H}-$ NMR," Carbohydrate Polymers, Vol. 61, No. 2, 2005, pp 155-161. doi:10.1016/j.carbpol.2005.04.006

[21] M. Lavertu, Z. Xia, A. N. Serreqi, M. Berrada, A. Rodrigues, D. Wang, M. D. Buschmann and A. A. Gupta, "A Validated ${ }^{1} \mathrm{H}$ NMR Method for the Determination of the Degree of Deacetylation of Chitosan," Journal of Pharmaceutical and Biomedical Analysis, Vol. 32, No. 6, 2003, pp. 1149-1158. doi:10.1016/S0731-7085(03)00155-9

[22] R. Rinaudo, M. Milas and P. L. Dung Inern, "Characterization of Chitosan. Influence of Ionic Strength and Degree of Acetylation on Chain Expansion," International Journal of Biological Macromolecules, Vol. 15, No. 5, 1993, pp. 281-285. doi:10.1016/0141-8130(93)90027-J

[23] R. A. A. Muzzarelli, A. Ferrero and M. Pizzoli, "LightScattering, X-Ray Differaction, Elemental Analysis and Infrared Spectroscopy Characterization of Chitosan, a Chelating Polymer," Talanta, Vol. 19, No. 10, 1972, pp. 1222-1226. doi:10.1016/0141-8130(93)90027-J 